\title{
Re-testing Wagner's Law: Structural breaks and disaggregated data for South Africa
}

\author{
Mthokozisi Mlilo, Matamela Netshikulwe \\ Faculty of Commerce, Law and Management, University of the Witwatersrand, Johannesburg, South Africa \\ mthokozisi.mlilo@wits.ac.za
}

\begin{abstract}
Direction of causality between government expenditure and output growth is pertinent for a developing country since a sizeable volume of economic resources is in the hands of the public sector. This paper investigates the Wagner's law in South Africa over the post-apartheid era, 1994-2015. This paper is unique to present studies since it uses disaggregated government expenditure and controls for structural breaks. The Granger non-causality test of Toda \& Yamamoto, a superior technique compared to conventional Granger causality testing, is employed and this paper finds no support for Wagner's law. However, there is causality running from total government and education expenditures to output. This finding is in line with the Keynesian framework. It is recommended in the paper that the government should take an active role in promoting output growth through increases in education expenditures in particular.
\end{abstract}

Keywords: Wagner's law; Granger causality; dis-aggregated government expenditures; Structural breaks; South Africa

\section{Introduction}

The government's expenditure in South Africa hogged the limelight recently, with calls for fiscal consolidation amid a looming ratings downgrade. It would seem that by curbing government expenditure growth, the South African economy's economic outlook might improve. However, this would depend on the causal relationship between an economy's output growth and government expenditure. Debates on the relationship between the size of government expenditure(s) and economic growth have been going on for centuries now. These debates stem chiefly from theories proposed by Adolph Wagner (1893) and John Maynard Keynes (1936), and are popularly known as the Wagner's law and the Keynesian hypothesis respectively (Henrekson, 1993). Theories of these scholars differ markedly as the Wagner's law proposes that there is a long-run tendency for government activities to grow relative to economic activity, with government expenditure viewed as an endogenous factor; while the Keynesian hypothesis proposes the reverse of Wagner's law and sees government expenditure as an exogenous factor. The difference is the direction of causation. Various theories, see, Mueller (2003:ch. 21) for a discussion, and empirical studies form part of the existing literature on this debate. Yet a general consensus is lacking. The challenges of poverty alleviation and socio-economic development remain central to the South African government's list of objectives. Government intervention through social-welfare spending programs is seen as a panacea in South Africa. However, these efforts have been viewed as unsustainable and inefficient. The Keynesian school of thought deems fiscal policy as one of the possible drivers of economic growth and poverty alleviation (Keynes, 1936). On the contrary, according to Wagner's law, economic growth drives the need for better social and economic services which increases government expenditure in the process (Wagner, 1893). In public finance literature, government seeks to achieve these objectives through its role of allocating and distributing resources to its citizens (Musgrave and Musgrave, 1988).

There is a concern over the continuous rise in general government expenditures amongst developing countries (Frimpong \& Oteng-Abiye, 2009). South Africa has faced a sustained and continuous budget deficit position in the past 20 years, bar years 2005-7, which is attributed to the ever increasing relative size of government and its components (National Treasury, 2016; Rossouw, Joubert \& Breytenbach, 2014). This continual hike in government expenditure strikes the hearts of many South Africans whose pockets are deeply dug by the hand of taxes. Increasing government expenditure is not in itself evil in the society as it may be an indication that social services are provided to the citizens. An inquiry over the presence of Wagner's hypothesis or its opposite, the Keynesian hypothesis, is important for policy formulation and review. A number of empirical studies on the direction of causation, concentrating on or including South Africa, have found mixed and/or divergent results. Even for other countries, developed and developing, single and intercountry analysis fails to reach a general consensus. Despite the divergent results, there is also evidence for 
bidirectional causality and no causality between output and government expenditure (Abbas \& Afzal, 2010). These varying results create a source of contention among economists hence the plethora of studies.

Empirical work testing Wagner's law in South Africa is contradictory. Some studies have found Wagner's law valid over some periods and invalid over other periods using various empirical techniques (for example see, Ziramba, 2008; Menyah \& Wolde-Rufael, 2012). Government operations are crucial for a developing country like South Africa, where the public sector absorbs a significant share of a country's economic resources, it is important that causality between public expenditure and economic growth is investigated. The causal relationship between output and government expenditure is contemporary and relevant in the face of accelerated government expenditure growth, stagnated economic growth and the calls for fiscal consolidation. This paper's innovation is on retesting Wagner's law by (1) controlling for the possibility of structural breaks, (2) making use of robust econometric techniques and (3) using disaggregated government expenditure data. It is possible that components of government expenditure affect output in different ways that cannot be detected when using total government expenditure data only (Frimpong \& Oteng-Abiye, 2009; Magazzino, 2011), hence the use of disaggregated government expenditure data. Structural breaks are incorporated since not allowing for an existing break leads to a bias that affects inferences (Perron, 1989) and conclusions on causality.

To our knowledge, none of the existing studies done on South Africa has controlled for structural break(s) in the data nor looked at disaggregated government expenditure for South Africa. This leaves a void in the existing literature worth filling as suggested by Frimpong \& Oteng-Abiye (2009). According to Frimpong \& Oteng-Abiye (2009) there is a possibility that components of government expenditure could better explain GDP while total government expenditure itself does not. Such a study, as this one, is critical particularly in South Africa where the government is geared towards fiscal consolidation. This paper contributes to the extant literature on Wagner's law by adding to the ongoing debate on government expenditures and output nexus. The remainder of the paper is organized as follows: section 2 reviews theoretical and existing empirical literature; section 3 presents the data and methodology; section 4 presents the results and section 5 concludes the paper.

\section{Literature Review}

Theoretical: Wagner's law has long been central to economic investigations since its discovery towards the end of the 19th century (Gupta, 1967; Peacock \& Wiseman, 1961). This law posits that government expenditure is an endogenous factor that is driven by output growth (Wagner, 1893). According to Wagner, an increase in government spending is seen as the product of economic development. Wagner gave three reasons to justify this hypothesis: 1) economic development results in the expansion of cultural and welfare expenditures; 2) government intervention may be needed to manage and finance natural monopolies; 3) private activities would be substituted by public activities (Bird, 1971). There are various versions of the Wagner's law tested in the literature. The predominant ones take the mathematical forms in table 1:

Table 1: Several versions of Wagner's law

\begin{tabular}{llc}
\hline No. & \multicolumn{1}{c}{ Functional form } & Source \\
\hline 1 & $\ln \mathrm{G}_{\mathrm{t}}=\alpha_{1}+\beta_{1} \ln \mathrm{GDP}_{\mathrm{t}}+\mu_{\mathrm{t}}$ & Peacock \& Wiseman (1961) \\
2 & $\ln \mathrm{G}_{\mathrm{t}}=\alpha_{2}+\beta_{2} \ln (\mathrm{GDP} / \mathrm{P})_{\mathrm{t}}+\mu_{\mathrm{t}}$ & Goffman (1968) \\
3 & $\ln (\mathrm{G} / \mathrm{GDP})_{\mathrm{t}}=\alpha_{3}+\beta_{3} \ln (\mathrm{GDP} / \mathrm{P})_{\mathrm{t}}+\mu_{\mathrm{t}}$ & Musgrave (1969) \\
4 & $\ln (\mathrm{G} / \mathrm{P})_{\mathrm{t}}=\alpha_{4}+\beta_{4} \ln (\mathrm{GDP} / \mathrm{P})_{\mathrm{t}}+\mu_{\mathrm{t}}$ & Gupta (1967) \\
5 & $\ln (\mathrm{G} / \mathrm{GDP})_{\mathrm{t}}=\alpha_{5}+\beta_{5} \ln \mathrm{GDP} \mathrm{t}+\mu_{\mathrm{t}}$ & Mann (1980) \\
\hline
\end{tabular}

where, In denotes the natural logarithm, G is government spending, GDP is real Gross Domestic Product and P is population, GDP/P denotes real GDP per capita, G/GDP is share of real government expenditure in GDP, $\mathrm{G} / \mathrm{P}$ is real government expenditure per capita and $\mu_{\mathrm{t}}$ is a serial uncorrelated random error term. Wagner's law implies that the real income elasticity coefficient should exceed unity in versions 1,2 , 4, (i.e., $\beta_{1}, \beta_{2}, \beta_{4}>1$ ) and should be greater than zero in versions 3,5 (i.e., $\beta_{3}, \beta_{5}>0$ ). A critical discussion on the versions of the law can be found in Henrekson (1993), Mann (1980) and Tarschys (1975). The inverse of this viewpoint is the Keynesian hypothesis which states that GDP is a function of government spending, where causality runs from 
government spending to GDP (Biswal, Dhawan \& Hooi-Yean, 2010). The Keynesian hypothesis is a product of John Maynard Keynes (1936)'s seminar book. Keynes postulated that the great depression was caused by low levels of aggregate demand in relation to aggregate supply. According to Keynes, the remedy was to simply increase government spending as a way of boosting output to its potential level.

Empirical Review: Ghorbani \& Zarea (2009), show that Wagner's law is confirmed in the Iranian economy for the period of 1960-2000 (using six Wagner's law versions). However, the study shows a lack of a long-run relationship between G and GDP after carrying out an Engle-Granger cointegration test. Furthermore, Ghorbani \& Zarea conclude that invisibility of a long-run relationship does not mean it does not exist; they suggest that a lack of a long-run relationship could be the result of structural breaks or the shortness of the sample time period investigated. The Ghorbani \& Zarea (2009)'s study failed to control for the possibility of structural breaks and perhaps this distorted their results. It is possible that neither the Wagner's law nor the Keynesian hypothesis holds such that G and GDP are regarded to be independent. A study by Frimpong \& Oteng-Abiye (2009) for three West African Monetary Zone (WAZM) countries; Gambia, Ghana and Nigeria finds neither the Wagner's law nor the Keynesian hypothesis valid for the period 1965-2004 in all countries. Also in another study, Ansari, Akuamoah \& Gordon (1997) finds no causal relationship between G and GDP in South Africa and Kenya for the period 1957-1990. Furthermore, Frimpong \& Oteng-Abiye (2009)'s study asserts that such results are possible if non-economic factors are more important in explaining the growth of government expenditure than economic factors. Their findings also indicate that government expenditure does not play a significant role in promoting economic growth. Frimpong \& Oteng-Abiye (2009)'s assertion is validated by Haque \& Hussain (2016) who argue that institutional factors do play a more significant role in explaining economic growth.

The time period investigated matters. Some countries show different results depending on the time period studied. For Ghana, as mentioned earlier on Frimpong \& Oteng-Abiye (2009), Wagner's law is found invalid for the period 1965-2004. However, in Ansari et al. (1997)'s study of the Wagner's law in Ghana, South Africa and Kenya over the period 1957-1990 it is found that Wagner's law is valid for Ghana. This case of varying results by period has also been found for Turkey in periods 1950-1960 and 1947-1967 (see, Krzyzaniak, 1972; Onder, 1974). Focusing on South Africa, Ziramba (2008) uses an autoregressive distributive lag (ARDL) bounds test approach to cointegration by Pesaran, Shin \& Smith (2001) and Granger non-causality procedure by Toda \& Yamamoto (1995) to test for Wagner's law for the period 1960-2006. The Toda-Yamamoto procedure has been found to be superior to the ordinary Granger causality test (see, Toda \& Yamamoto, 1995). Ziramba (2008) results show bidirectional causality between per capita G and per capita GDP. Ziramba tentatively concludes that there is no support for Wagner's law in South Africa. Menyah \& Wolde-Rufael (2012) reassessed the validity of Wagner's law in South Africa by extending Ziramba's period of study from 1950-2007. The extended sample period was meant to mitigate the finite sample bias problem associated with a small sample. In Menyah \& Wolde-Rufael (2012) they apply five long-run estimators: the ARDL, Dynamic Ordinary Least Squares, Fully modified Ordinary Least Squares, Maximum likelihood estimators and Ordinary least squares. They find evidence of causality from GDP to government expenditure, supporting Wagner's law. Furthermore, Menyah \& Wolde-Rufael (2012)'s study finds that the size of South Africa's public sector is significant and positively related to GDP over the period 1950-2007. This difference in results with Ziramba could be due to the differences in the econometric methodology and the sample period/size. Neither Ziramba (2008) nor Menyah \& Wolde-Rufael (2012) studies seem to have explicitly taken structural breaks into account and this could have been one of the reasons why their results are not similar.

Keho (2015) looks at ten African countries for the period 1965-2013 and finds varying Wagner's law results for each. The paper employs Granger causality tests in the frequency domain (phase resampling method) which allows distinguishing between short, medium and long run causality. Wagner's law is found valid for Ghana in the short, medium and long terms; for Cameroon in medium term and only in long-run for Nigeria. The law is not found valid for Gabon, South Africa and Senegal in short and medium terms. Both Wagner's hypothesis and its counterpart, Keynesian hypothesis, are valid for Burkina Faso in short, medium and long terms. Phase resampling is a robust method for making statistical inferences even with short-time series and yields satisfactory type I and type II error rates (Liu \& Molenaar, 2016). These results disagree with that of Ziramba (2008) and Menyah \& Wolde-Rufael (2012) for South Africa which finds causality for the short-run and Ansari et al. (1997)'s results for Ghana. The variation in results can still be attributed to different 
econometric techniques employed or versions of the Wagner's law employed. Looking at the South-East Asian countries over the period 1960-2002, Dogun \& Tang (2006) employ simple Granger-causality test and find no support for Wagner's law for all countries in the region. However, they find Keynesian hypothesis for Philippines and no cointegration for all countries, but Indonesia. The period under investigation coincides with the East-Asian financial crisis; an increase in government expenditure is expected in order to stimulate the economy according to the Keynesian hypothesis.

Few studies have studied Wagner's law using disaggregated data for some countries. Biswal et al. (2010) investigates whether growth of total government expenditure and its components have short-run or long-run relationship with GDP in Canada for the period 1950-1995. Bidirectional causality is found between total government expenditure and GDP while short-run causation in the Wagnerian sense is found between GDP and components of government expenditure inclusive of transfer payments to business and persons, government investment and wages of civilian and military personnel. Ighodaro \& Oriakhi (2010) studied Wagner's law in Nigeria for the period 1961-2007 using disaggregated government expenditure data and validated Keynesian hypothesis rather than Wagner's law over total and some components of government expenditure. It is noteworthy that components of government expenditure might have individual significant roles in the economic process. Government expenditure and GDP relationship has important policy implications hence it has attracted considerable interest among economists and policy makers. This has led to a superfluity of empirical studies and various findings although there is no general consensus. The divergence in results can be attributed to the evolution of econometric techniques with earlier studies not looking at stationarity of variables, whilst recent studies investigate the presence of a long-run relationship and test for Granger causality between variables of interest (Sideris, 2007). The results also seem to differ depending on whether an economy is a developing or a developed one (Ghorbani \& Zarea, 2009).

\section{Methodology}

Data and justification of variables: This study uses real Gross Domestic Product per capita (Y), total government expenditure $(G)$, government expenditure on education (E), government expenditure on health (H) and Population (P) data obtained from the World Bank for the period 1994-2015, which is the postapartheid era. Real GDP is chosen as a widely used macro-economic indicator to depict output of an economy. $\mathrm{G}$ is chosen as an indicator of the country's government expenditure inclusive of productive and nonproductive expenditures. Since this paper seeks to determine the relationship between $G$ and $Y$, these then stand as core variables of interest. As stated earlier, components of G may affect real GDP per capita in different ways that may not be detected when using G data only. On this reason, this paper makes use of the components of G which are E and H. Further, annual data is used based on Singh \& Sahni (1984) argument that $\mathrm{G}$ is hardly sensitive to seasonal and even cyclical fluctuations. All level variables are deflated using a GDP deflator with year 2010 as the base year.

Estimation technique: The causal relationship between GDP and G (total and disaggregated government expenditure) is determined through a three-step procedure; unit-root testing, cointegration and causality testing. The following Wagner's law version of functional form by Gupta (1967) is used:

$$
\ln (G / P)_{t}=\alpha_{1}+\beta_{1} \ln (G D P / P)_{t}+\mu_{t}
$$

Where $\mu_{\mathrm{t}}$ is a serial uncorrelated random error term and $\beta_{1}$ is the elasticity of G with respect to GDP. Interpretation of equation 1 is that $G$ should increase by a higher rate than GDP, i.e., $\beta_{1}>1$ if Wagner's law is present.

Unit root test: Most of the macroeconomic time series data exhibit non-stationary processes (Perron, 1989). The mean, variance and covariance of time series data are time-dependent and varying which can deliver unreliable estimated results (Gujarati \& Porter, 2009). Failure to test for stationarity in time series analysis can lead to the problem of spurious regressions. A non-stationary time series can be made stationary through differencing such that the series becomes integrated of order $s$, where $s$ is the number of times it is differenced to become stationary. If a time series is stationary at levels then it is integrated of order zero, $I(0)$, and integrated of order $d, I(d)$, if differenced $d$-times. In general, various tests are employed to study stationarity properties of time series data such as the Dickey-Fuller (DF) (1979) test, Augmented DickeyFuller (ADF) (1979) test and the Phillips-Perron (PP) (1988) test. This paper employs ADF and PP tests to 
determine the existence of unit roots in the data. The ADF is superior to the DF as it incorporates autocorrelation by assuming that the series follows an auto-regressive process of order $p$. It is chosen over the DF for its consistency and accuracy. The general form of the ADF equation including intercept and trend is:

$$
\Delta Y_{t}=\alpha+\beta t+\delta Y_{t-1}+\sum_{k=1}^{n} \phi_{k} \Delta Y_{t-k}+\epsilon_{t}
$$

Where $n$ is the number of lags, $t$ indicates time and $\Delta Y_{t}$ represents first difference of series $Y_{t}$. Appropriate lag length is chosen using the information criterion, i.e., the Akaike Information Criterion (AIC), Schwartz Bayesian Criterion (SBC) and the Final Prediction Error (FPE). The null hypothesis is:

$$
H_{0}: \delta=0
$$

against

$$
H_{1}: \delta \neq 0
$$

Rejecting $H_{0}$ proves the series under consideration is stationary.

The PP test is used for robustness and reliability test in this paper. The PP test differs with ADF test on how it corrects serial correlation and heteroscedasticity. The PP test corrects non-parametrically by modifying the DF test statistics while the ADF test corrects by adding lag terms in the series. The PP test general form of equation including the trend and intercept is:

$$
\Delta Y_{t}=\alpha+\beta_{t}+\rho Y_{t-1}+\mu_{t}
$$

where $\mu_{t}$ is integrated of order one and may be heteroskedastic. The null hypothesis is:

$$
\begin{array}{ll} 
& H_{0}: \rho=0 \\
\text { against, } & H_{1}: \rho \neq 0
\end{array}
$$

rejecting $H_{0}$ proves series under consideration is stationary.

From the background analysis, structural break(s) is(are) suspected in some variables under consideration. Failure to allow for an existing break leads to a bias that reduces the ability to reject a false unit-root (Perron, 1989). The above mentioned tests potentially confuse structural breaks in the series as evidence of nonstationarity (García, Gitau \& Ndirangu, 2014) hence a number of studies have developed unit root tests that incorporate structural breaks (see, Andrews \& Zivot, 1992; Bai \& Perron, 2003; Clemente, Montañés \& Reyes, 1998; Lumsdaine \& Papell,1997; Perron, 1989; Perron \& Vogelsand, 1998). These tests determine the break points in a time series and reduce bias in the unit root tests. This paper employs the Andrews \& Zivot (1992) and Clemente et al. (1998) unit root tests. These tests have the ability to determine the break point endogenously from the data which provides valuable information for analysing whether a structural break on a time series is associated with a particular government policy, economic crises, war, regime shift or other factors (Glynn, Perera \& Verma, 2007). The stationarity test by Andrews \& Zivot (1992) allows for one structural break within the observed history of a time-series. This test extends the unit root test of Perron (1989). They differ in that Andrews \& Zivot (1992) test determines the breakpoint endogenously and uses the innovational outlier (IO) model, while Perron (1989)'s test determines the breakpoint exogenously and uses the two-step additive outlier (AO) model. AO model allows for gradual shift in the mean of the series while the IO model captures sudden change in the series. The Andrews \& Zivot test performs one of the following regressions to test for a unit root depending on the nature of a time series:

$$
\begin{aligned}
& y_{t}=\mu+\theta D U_{t}(\lambda)+\beta t+\alpha y_{t-1}+\sum_{j=1}^{k} c_{j} \Delta y_{t-j}+e_{t} \\
& y_{t}=\mu+\gamma D T_{t}^{*}(\lambda)+\beta t+\alpha y_{t-1}+\sum_{j=1}^{k} c_{j} \Delta y_{t-j}+e_{t} \\
& y_{t}=\mu+\theta D U_{t}(\lambda)+\gamma D T_{t}^{*}(\lambda)+\beta t+\alpha y_{t-1}+\sum_{j=1}^{k} c_{j} \Delta y_{t-j}+e_{t}
\end{aligned}
$$

where $\lambda=T_{B} / T$ is the breakpoint, $T_{B}$ is the break date; dummy representing change in levels $D U_{t}(\lambda)=1$ if $t>T$ $\lambda, 0$ otherwise; dummy representing change in slope $D T_{t}^{*}(\lambda)=t-T \lambda$ if $t>T \lambda, 0$ otherwise. Equation 4 allows 
change in the level of the series, equation 5 allows change in the rate of growth and equation 6 allows both changes (Andrews \& Zivot, 1992). The null hypothesis for the three models is based on the model below:

$$
y_{t}=\mu+\alpha y_{t-1}+e_{t}
$$

The series $y_{t}$ is integrated without an endogenous structural break (equivalent to testing that $\alpha=1$ in the models), while the alternative hypothesis is that $y_{t}$ can be represented by a trend-stationary process with a one-time break in the trend. The test aims to estimate the breakpoint that gives the most weight to the trendstationary alternative (Andrews \& Zivot, 1992). Some macro-economic time series may exhibit multiple breaks and would require models that allow a large number of breaks. The Clemente et al. (1998) test extends the unit root test of Perron \& Vogelsang (1992) to the case where the time series exhibits a double change in the mean. If the shifts are better represented by additive outliers (AO), the following two-step procedure is performed (Clemente et al., 1998):

$$
y_{t}=\mu+d_{1} D U_{1 t}+d_{2} D U_{2 t}+\tilde{y}_{t}
$$

where equation 8 is estimated so as to remove the deterministic part of the variable. This is then followed by estimating equation 9 :

$$
\tilde{y}_{t}=\sum_{i=0}^{k} \omega_{1 i}(D T B)_{1 t-i}+\sum_{i=0}^{k} \omega_{2 i}(D T B)_{2 t-i}+\rho \tilde{y}_{t-1}+\sum_{i=1}^{k} c_{i} \tilde{y}_{t-i}+e_{t}
$$

and testing whether the autoregressive parameter $\rho$ is equal to 1 for all possible break times.

If the shifts are better represented by the innovational outlier (IO), the following model in equation 10 is estimated and then a test of whether the autoregressive parameter $\rho$ is equal to 1 for all possible break points (Clemente et al., 1998):

$$
y_{t}=\mu+\rho y_{t-1}+\delta_{1}(D T B)_{1 t}+\delta_{2}(D T B)_{2 t}+d_{1} D U_{1 t}+d_{2} D U_{2 t}+\sum_{i=1}^{k} c_{i} \Delta y_{t-i}+e_{t}
$$

where the pulse variable $(D T B)_{i t}=1$ if $t=T B_{i}+1$ for $(i=1,2)$ and 0 otherwise; dummy representing change in levels $D U_{i t}=1$ if $t>T B_{i}$ for $(i=1,2)$ and 0 otherwise; $T B_{1}$ and $T B_{2}$ are the break points/dates when the mean is shifting.

Cointegration: Economic variables are said to be cointegrated if there is a long-run relationship between them to which the system converges to. Although series may be non-stationary at levels with integration order of $r$, their linear combination can be stationary with integration order of $r$-1. Johansen \& Juselius (1990) approach is employed to test for cointegration between variables of interest. This test is a widely used technique for testing for cointegration (Frimpong \& Oteng-Abiye, 2009) due to its observed superiority over other procedures (Magazzino\& Forte, 2010). Amongst major advantages of Johansen's cointegration procedure is that there is little need to pre-test the variables in the system to establish their order of integration (Johansen, 1995). The Johansen procedure works well in large samples because of its asymptotic properties and likely to have small sample bias; and it assumes that the cointegrating vector is constant during the period of study (Ssekuma, 2011). However, due to technological progress, policy changes, economic crisis and other reasons; cointegration between variables under consideration changes in time. Empirical studies show that the tests for cointegrating ranks in Johansen procedure are sensitive to the values of the nuisance parameters in finite samples (Reimers, 1992; Toda \& Yamamoto, 1995) and possibly sensitive to structural breaks. Although, the Johansen procedure is deemed powerful throughout literature, this paper employs a cointegration test with structural breaks by Gregory \& Hansen (1996) as a check for the robustness and reliability of the results. Gregory \& Hansen (1996)'s test, thereafter Ghansen test, is a residual based test which is an extension of the traditional ADF, Phillips' $Z \alpha$ and $Z_{t}$ type of tests designed to test the null of no cointegration against the alternative of cointegration in the presence of a possible structural break(s) at an unknown time. Gregory \& Hansen indicate that the motive of these tests is derived from the conventional notion of regime change in a time series relationship. The Ghansen test is used as a robustness check on Johansen's test in the presence of structural breaks.

Direction of causation: In the presence of structural breaks, the linearity assumption in the regression equations of a vector auto-regression (VAR) system can lead to a misspecified model which can affect the outcome of Granger causality testing, leading to erroneous conclusions (Bianchi, 1995; Lütkepohl, 1989). Instead, this paper employs the Granger non-causality test using a modified Wald (MWald) test proposed by 
Toda \& Yamamoto (1995). The Toda and Yamamoto procedure provides a simple way to deal with challenges encountered in hypothesis testing when VAR processes are likely to have unit roots. Toda and Yamamoto method is applicable whether the VAR is stationary, integrated of an arbitrary order, or cointegrated of an arbitrary order. Most pertinently with this procedure, "less attention is paid to the integration and cointegration properties of the time series data at hand when estimating this averts the possibility of pre-test bias" (Toda \& Yamamoto, 1995). The procedure requires the determination of a maximal order of integration $c$ and the true lag order $m$ in the system which clears any serial correlation, where $c$ is not greater than $m$. Lag order is selected using the information criterion. The Lagrange Multiplier test is performed to test for serial correlation at the optimal lag. If serial autocorrelation is found then the optimal lag order is increased to the lag order that clears serial correlation. The VAR is overfitted with order $p=m+c$ to get the Granger causality test statistics with standard asymptotic distributions. The MWald statistic is derived when $p^{\text {th }}$ order VAR in equations 11 and 12 is estimated which follows an asymptotic $\chi^{2}$ distribution with $m$ degrees of freedom (see, Theorem 1 of Toda \& Yamamoto (1995)):

$$
\begin{aligned}
& \ln Y_{t}=\alpha_{0}+\sum_{i=1}^{m} \alpha_{1 i} \ln Y_{t-i}+\sum_{j=m+1}^{c} \alpha_{2 j} \ln Y_{t-j}+\sum_{i=1}^{m} \delta_{1 i} \ln X_{t-i}+\sum_{j=m+1}^{c} \delta_{2 j} \ln X_{t-j}+\varepsilon_{1 t} \\
& \ln X_{t}=\beta_{0}+\sum_{i=1}^{m} \beta_{1 i} \ln X_{t-i}+\sum_{j=m+1}^{c} \beta_{2 j} \ln X_{t-j}+\sum_{i=1}^{m} \phi_{1 i} \ln Y_{t-i}+\sum_{j=m+1}^{c} \phi_{2 j} \ln Y_{t-j}+\varepsilon_{2 t}
\end{aligned}
$$

A null hypothesis of Granger non-causality is set and its rejection proves the presence of Granger causality. Toda \& Yamamoto (1995) do not suggest that their method should totally replace the conventional hypothesis testing techniques that are conditional on the estimation of unit roots and cointegrating ranks. Toda and Yamamoto advise that their technique should be regarded as complementing the pretesting methods that may suffer serious biases in some cases. This paper thus maintains the three-step procedure for causality testing.

\section{Results and Discussion}

Variables Y, G, E and Hare per capita variables and estimations are based on the Gupta (1967) version of Wagner's law.

\section{Unit root testing}

Structural break(s): The presence of structural breaks is determined before we test for unit roots. Results of the Chow (1960) test for structural breaks indicate that a structural break exists in the Y, G and $\mathrm{H}$ time series for the period under investigation and not in E. Table 2 shows the Chow test results at the $1 \%$ level of significance.

Table 2: Chow test

\begin{tabular}{lc}
\hline Variable & Chow test stat \\
\hline & \\
Y & $14.01^{* * *}$ \\
G & $6.15^{* * *}$ \\
$\mathrm{E}$ & 1.15 \\
$\mathrm{H}$ & $11.27^{* * *}$ \\
\hline
\end{tabular}

Source: Author's calculations; ${ }^{* * *}$ indicates $1 \%$ significance level.

The Chow test only affirms the presence of a structural break while in the following subsections, Clemente et al. (1998) and Andrews \& Zivot (1992) tests provide the break points.

Unit root testing without structural break(s): ADF and PP unit root tests are performed for E without structural breaks. The E series is found to be integrated of order one, I(1), shown in Table 3. 
Table 3: Unit root tests

\begin{tabular}{llll}
\hline Variables & Test & Levels & \multicolumn{1}{c}{ 1 $^{\text {st }}$ difference } \\
\hline E & ADF & 1.158 & $-1.914^{*}$ \\
& PP & 1.370 & $-2.889^{* * *}$ \\
\hline
\end{tabular}

Source: Author's calculations; ${ }^{* * *},{ }^{*}$ indicates $1 \%$ and $10 \%$ significance levels respectively.

Unit root testing under structural break(s): $G$ and $H$ are found to have two structural breaks using the Clemente et al. (1998) test while Y is found to have one structural break using the Andrews \& Zivot (1992) test. The Clemente's innovational outlier model (Clemio) is employed instead of the additive outlier model (Clemao) for $\mathrm{Y}$ and $\mathrm{G}$ because the time series are better explained by a gradual shift and not a sudden change in the mean. However, the additive outlier is employed for $\mathrm{H}$ since it exhibits a sudden change in the mean. Table 4 exhibits unit root results, GDP and $\mathrm{H}$ are found to be integrated of order $2, I(2)$, and $\mathrm{G}$ is found to be integrated of order $1, I(1)$.

Table 4: Unit root tests

\begin{tabular}{lccccc}
\hline Variables & Test & Levels & $\mathbf{1}^{\text {st }}$ difference & $\mathbf{2}^{\text {nd }}$ difference & Break(s) \\
\hline Y & ZAndrews & -3.475 & & -4.842 & 2008 \\
G & Clemio & -5.247 & $-5.704^{* *}$ & & $2000 \& 2009$ \\
H & Clemao & -4.096 & & $-15.07^{* *}$ & $1998 \& 2009$ \\
\hline
\end{tabular}

Source: Author's calculations; ${ }^{* *}$ indicates $5 \%$ significance level

The identified structural breaks are significant and can be linked to the 1997/8 East Asian financial crisis and the 2008/9 global financial crisis. With integrating orders of time series and structural break points known, robust elasticities can be estimated with more confidence against spurious results; this is demonstrated in the next section.

Elasticity estimates: Table 5 shows the elasticity estimates based on data in its levels and differenced form. Estimates based on data in levels indicate elasticity estimates above one indicating greater possibility of the Wagner's law hypothesis (Sideris, 2007). However, the results based on levels are not to be taken without caution as the time series could be non-stationary which renders the results spurious (Henrekson, 1993).

Table 5: Elasticity estimates

\begin{tabular}{llll}
\hline Functional form & Direction & Levels & Differenced \\
\hline \multirow{4}{*}{ Gupta } & & & \\
& $\ln \mathrm{Y} \rightarrow \ln \mathrm{G}$ & 1.29 & 0.02 \\
\multirow{4}{*}{ Functional form } & $\ln \mathrm{Y} \rightarrow \ln \mathrm{E}$ & 1.17 & 0.47 \\
& $\ln \mathrm{Y} \rightarrow \ln \mathrm{H}$ & 1.04 & -0.34 \\
Gupta & Direction & Levels & Differenced \\
& & & \\
& $\ln \mathrm{G} \rightarrow \ln \mathrm{Y}$ & 0.74 & 0.014 \\
& $\ln \mathrm{E} \rightarrow \ln \mathrm{Y}$ & 0.57 & 0.094 \\
& $\ln \mathrm{H} \rightarrow \ln \mathrm{Y}$ & 0.78 & -0.129 \\
\hline
\end{tabular}

Source: Author's calculations. Estimated at the $5 \%$ level of significance

The differenced results are based on regressions performed with respect to the order of integration determined subject to structural breaks. Using level data, elasticity estimates are less than one implying a unit percentage change in Y yields a less than unit percentage change in $G, E$ and $H$ (refer to the upper block in table 5). The size of the elasticity between G and Y (i.e. 1.29) is comparable with other studies for South Africa using post-apartheid era level data. However, once we difference the data the elasticities become less than one highlighting a case of a possible spurious relationship in level data estimates.

Cointegration: Table 6 shows the results of the Johansen procedure to cointegration. There is no evidence of cointegration in all relationships at the $5 \%$ level of significance. 
Table 6: Johansen cointegration rank test

\begin{tabular}{|c|c|c|c|c|c|}
\hline Variables & $\begin{array}{l}\text { Hypothesized No } \\
\text {. of CE(s) }\end{array}$ & Max-eigenvalue stat & critical value & Trace stat & critical value \\
\hline \multirow[t]{2}{*}{$Y \& G$} & zero & 9.74 & $14.07^{* *}$ & 10.31 & $15.41^{* *}$ \\
\hline & At most 1 & 0.57 & $3.76^{* *}$ & 0.57 & $3.76^{* *}$ \\
\hline \multirow[t]{2}{*}{$Y \& H$} & zero & 10.58 & $14.07^{* *}$ & 13.5 & $15.41^{* *}$ \\
\hline & At most 1 & 2.92 & $3.76^{* *}$ & 2.92 & $3.76^{* *}$ \\
\hline \multirow[t]{2}{*}{$Y \& E$} & zero & 11.79 & $14.07^{* *}$ & 12.77 & $15.41^{* *}$ \\
\hline & At most 1 & 0.98 & $3.76^{* *}$ & 0.98 & $3.76^{* *}$ \\
\hline
\end{tabular}

Source: Author's calculations. ${ }^{* *}$, indicates 5\% significance levels; CE - Cointegration Equations

For robustness, the Ghansen test is performed for GDP, G and H relationships (those with structural breaks) and the results are shown in table 7. Since the Ghansen test is sensitive to the lag order used, the information criterion is employed for each relationship. The regime shift model is employed by allowing for the slope and intercept vectors to shift. The paper fails to reject the null hypothesis of no cointegration in all relationships with structural breaks.

Table 7: Gregory-Hansen test for cointegration with regime shifts

\begin{tabular}{llcc}
\hline Relationship & ADF & $\mathbf{Z}_{\mathbf{t}}$ & $\mathbf{Z}_{\boldsymbol{\alpha}}$ \\
\hline G \& Y & $-4.32^{* * *}$ & $-3.29^{* * *}$ & $-3.01^{* * *}$ \\
H \& Y & $-4.93^{* * *}$ & $-5.05^{* * *}$ & $-23.60^{* * *}$ \\
\hline
\end{tabular}

Source: Author's calculations; ${ }^{* * *}$ indicates $1 \%$ significance level

It is with confidence that there is no cointegration amongst the time series under consideration. It is common in studies testing Wagner's law to find a no cointegrating relationship (see, Ansari et al., 1997; Ghorbani \& Zarea, 2009; Frimpong \& Oteng-Abiye, 2009; Massan, 2015), however our result is at odds with Ziramba (1998). These studies suggest various possible reasons such as the time-period analysed not being sufficiently long to fully capture the long-run relationship and structural breaks which are incorporated in this paper. Some of these studies indicate that the existence of no cointegration implies that none of the variables in the system can be targeted as a policy variable in the long term. Nevertheless, this paper proceeds to causality testing since the aim is to determine if there is a causal link between the variables in the study. It is noteworthy that cointegration is a necessary but not sufficient condition for Wagner's law.

Causality: Due to varying integration orders of the time series in the system, this paper uses the Toda \& Yamamoto Granger non-causality test to determine whether there is a causal relationship between $\mathrm{G}$ and $\mathrm{Y}$ for the period under investigation. Table 8, shows the MWald test results and $p$-values for each relationship where the null hypothesis of no Granger causality is tested. The highest order of integration is 2 . The optimal lag orders are: 2 for $Y$ relationships with $\mathrm{G}$ and $\mathrm{E}$, and 4 for the relationship with $\mathrm{H}$ based on the AIC, SBC and FPE. In table 8, the upper block shows results for the Wagner's law causality test whilst the bottom block looks at the possibility of the Keynesian hypothesis.

Table 8: Toda-Yamamoto Granger non-causality results

\begin{tabular}{lccc}
\hline Cause & Effect & F test statistic & Decision \\
\hline $\ln \mathrm{Y}$ & $\ln \mathrm{G}$ & 2.33 & Fail to reject \\
$\ln \mathrm{Y}$ & $\ln \mathrm{E}$ & 2.17 & Fail to reject \\
$\ln \mathrm{Y}$ & $\ln \mathrm{H}$ & 10.80 & Fail to reject \\
$\ln \mathrm{G}$ & $\ln \mathrm{Y}$ & $19.32^{* *}$ & Reject \\
$\ln \mathrm{E}$ & $\ln \mathrm{Y}$ & $5.28^{* *}$ & Reject \\
$\ln \mathrm{H}$ & $\ln \mathrm{Y}$ & 4.22 & Fail to reject
\end{tabular}

Source: Author's calculations; ${ }^{* *}$ indicates 5\% significance level 
No evidence of serial correlation is found at the selected optimal lag orders. The results suggest a failure to reject the null hypothesis for all relationships in the upper block of table 8. There is no support for Wagner's law in South Africa for the total and disaggregated government expenditures. Using this technique, without considering structural breaks and using total government expenditure, Ziramba (2008) tentatively provides evidence in support of these results for South Africa by also concluding that there is no evidence of Wagner's law. Other studies using other techniques have also found similar results for various countries, some including South Africa (see, Ansari et al., 1997; Li, Li, Wang \& Zheng, 2010). On the bottom block of table 8, E and $G$ are found to be causing $Y$ since the null of no Granger causality is rejected at the $5 \%$ of significance. These results show evidence of a unidirectional causal relationship running from $G$ to $Y$ and $E$ to $Y$ thus supporting the Keynesian hypothesis in these two relationships. Keho(2015)'s study found the Keynesian hypothesis valid for South Africa only in the short and medium run by using a Granger causality test in the frequency domain. Neither the Wagner's law nor Keynesian hypothesis holds in relationships between health and GDP. This implies independence between GDP and health expenditures. It is worth noting that these results are, to some degree, corresponding to the elasticity estimates of differenced results in table 5 and cointegration results in table 6 and 7.

These findings are, only in parts, consistent with the other published studies done in this field as none have used disaggregated government expenditure data or incorporated structural breaks for South Africa; hence this study is not just a replication. According to Frimpong \& Oteng-Abiye (2009), non-causality is possible if non-economic factors are more important in explaining the growth of government expenditure than economic factors. In South Africa, there is a high and increasing government social assistance program through social grant services. SASSA (2016) indicates that about $31 \%$ of the South African population is receiving social grants from the government. This government expenditure is not driven by economic factors; restitution, political and moral factors seem to be dominant. This is expected in South Africa, to some degree, as the democratic government aims to redress the social and economic injustices of the apartheid-era by increasing social services expenditure. On the other hand, a causal link from total government expenditure and education expenditure to $\mathrm{Y}$ indicates that economic growth can be explained by these expenditures. A causal relationship is expected if an increase in education expenditure is used effectively such that it increases skills and the knowledge pool which in turn accelerates economic development. With the foregoing, South Africa's annual GDP growth declined from 3.2\% in 2011 to 1.3\% in 2015. One can argue that South Africa's GDP growth needs stimulation. Thus fiscal policy currently stands as a possible remedy to the South African economy considering that the Keynesian hypothesis holds.

\section{Conclusion and Recommendations}

This paper presents evidence, on the direction of causation between South Africa's GDP and disaggregated government expenditure, which is more robust and reliable when compared to previous studies since this paper controls for structural breaks. This paper tests Wagner's law and its reverse for South Africa between education expenditure, health expenditure, total government expenditure and GDP. The Gregory \& Hansen and Johansen cointegration tests are used for reliability and robustness and it is established that there is no cointegration in all relationships tested for South Africa in the period of 1994-2015. The results from the Toda - Yamamoto's Granger non-causality test indicates that Wagner's law is not valid in South Africa. This implies that there is no causal link from GDP to either total government expenditure or any of government expenditure variants studied. Furthermore, the Keynesian hypothesis is found valid for total government expenditure and education expenditure. This implies that growth of total government expenditure and education expenditure can be used as policy variables to stimulate economic growth.

The use of disaggregated government expenditure data is crucial in policy modelling as it determines the specific causal links. The findings of this paper suggest that in South Africa, tightening fiscal policy may not be good for economic growth based on the Keynesian hypothesis. From the Keynesian hypothesis, this paper suggests that government expenditure, in particular government expenditure on education, could be used to stimulate economic growth. Furthermore, the government should increase funding for education and post school training so as to reduce South Africa's skills gap which has been identified as a hindrance to economic growth. In particular, funding for the National Student Financial Aid Scheme (NSFAS) can be increased and help enrol more students into post school education. This paper suggests that future research should look at 
more components of total government expenditure to determine those that are relevant in stimulating the

South African economic growth.

\section{References}

Abbas, Q. \& Afzal, M. (2010). Wagner's law in Pakistan: Another look. Journal of Economics and International Finance, 2(1), 12-19. http://www.academicjournals.org/JEIF

Andrews, D. K. W. \& Zivot, E. (1992). Further Evidence on the Great Crash, the Oil-Price Shock, and the UnitRoot Hypothesis. Journal of Business \& Economic Statistics, 20(1), 25-44.

Ansari, M. I., Akuamoah, C. \& Gordon, D. V. (1997). Keynes versus Wagner: Public expenditure and national income for three African countries. Applied Economics, 29(4), 543-550. http://dx.doi.org/10.1080/000368497327038

Bai, J. \& Perron, P. (2003). Computation and analysis of multiple structural change models. Journal of Applied Econometrics, 18, 1-22. http://onlinelibrary.wiley.com/doi/10.1002/jae.659/pdf

Bianchi, M. (1995). Time series modeling in the presence of structural change. Manuscript, Universite Catholique de Louvain.

Bird, R. M. (1971). Wagner's law of expanding state activity. Public Finance, 26, 1-26.

Biswal, B., Dhawan, U. \& Hooi-Yean, L. (2010). Testing Wagner versus Keynesian using disaggregated public expenditure data for Canada. Applied Economics, 31(10), 1283-1291. http://dx.doi.org/10.1080/000368499323490

Chow, G. C. (1960). Tests of Equality between Sets of Coefficients in Two Linear Regressions. Econometrica, 28, 591-605.

Clemente, J., Montañés, A. \& Reyes, M. (1998). Testing for a unit root in variables with a double change in the mean. Economics Letters, 59(2), 175-182. http://dx.doi.org/10.1016/S0165-1765(98)00052-4

Dickey, D. A. \& Fuller, W. A. (1979). Distribution of the estimators for autoregressive series with a unit root. Journal of American Statistical Association, 74, 427-431.

Dogun, E. \& Tang, T. (2006). Government expenditure and national income: causality tests for five South-East Asian countries. International Business \& Economics Research Journal, 5(10), 49-58. http://www.cluteinstituteonlinejournals.com/PDFs/2006286.pdf

Frimpong, J. \& Oteng-Abiye, F. (2009). Does the Wagner's hypothesis matter in developing economies? Evidence from three West African monetary zone (WAZM) countries. American Journal of Economics and Business Administration, 1(2), 141-147.

García, C., Gitau, C. \& Ndirangu, L. (2014). Evidence of Structural Breaks in Kenya Macroeconomic Variables. Paper presented at CSAE 2014 conference, England, United Kingdom, 23-25 March 2014.

Ghorbani, M. \& Zarea, A. (2009). Investigating Wagner's law in Iran's economy. Journal of Economics and International Finance, 1(5), 115-121. http://www.academicjournals.orgJEIF

Glynn, G., Perera, N. \& Verma, R. (2007). Unit Root Tests and Structural Breaks: A Survey with Applications. Revista de m'etodos cuantitativos para la econom'ía y la empresa, 3, 63-79. http://www.upo.es/RevMetCuant/art11.pdf

Goffman, I. J. (1968). On the empirical testing of Wagner's law: A technical note. Public Finance, 23, 359-366.

Granger, C. W. J. (1988). Some recent developments in a concept of causality. Journal of Economics, 39, 199211.

Gregory, W. A. \& Hansen, B. E. (1996). Residual-based tests for cointegration in models with regime shifts. Journal of Econometrics, 70, 99-126.

Gujarati, D. N. \& Porter, C. D. (2009). Basic Econometrics (5th ed). New York: McGraw-Hill/Irwin.

Gupta, S. P. (1967). Public expenditure and economic growth: A time series analysis. Public Finance, 22, 423471.

Haque, M. \& Hussain, E. M. (2016). Impact of Economic Freedom on the Growth Rate: A Panel Data Analysis. Economies, 4(2), 5. http://www.mdpi.com/2227-7099/4/2/5

Henrekson, M. (1993). Wagner's law: A spurious relationship? Public Finance, 48, 406-415.

Ighodaro, A. U. \& Oriakhi, D. E. (2010). Does the relationship between government expenditure and economic growth follow Wagner's law in Nigeria? Annals of the University of Petrosani. Economics, 10(2), 185198.

Johansen, S. (1995). Likelihood-Based Inference in Cointegrated Vector Autoregressive Models. Oxford: Oxford University Press. 
Johansen, S. \& Juselius, K. (1990). Maximum likelihood estimation and inference on cointegration: with applications to the demand for money. Oxford Bulletin of Economics and Statistics, 52(2), 169-210.

Keho, Y. (2015). Revisiting Wagner's Law for Selected African Countries: A Frequency Domain Causality Analysis. Journal of Statistical and Econometric Methods, 4(4), 55-69.

Keynes, J. M. (1936). The general theory of employment, interest and money. London: Macmillan and Co. limited.

Krzyzaniak, M. (1972). The Case of Turkey: Government Expenditures, the Revenue Constraint and Wagner's Law. Program of Development Studies, Paper No. 19. Houston: Rice University.

Li, C., Li, J., Wang, X. \& Zheng, Y. (2010). An Empirical Analysis of the Validity of Wagner's Law in China: A Case Study Based on Gibbs Sampler. International Journal of Business and Management, 5(6). http://dx.doi.org/10.5539/ijbm.v5n6p161.

Liu, S. \& Molenaar, P. (2016). Testing for Granger Causality in the Frequency Domain: A Phase Resampling Method. Multivariate Behavioural Research, 53-66. http://dx.doi.org/10.1080/00273171.2015.1100528.

Lumsdaine, R. \& Papell, D. (1997). Multiple Trend Breaks and the Unit-Root Hypothesis. The Review of Economics and Statistics, 79(2), 212-218. http://www.jstor.org/stable/2951453

Lütkepohl, H. (1989). The stability assumption in tests of causality between money and income. Empirical Economics, 14(2), 139-150. http://link.springer.com/article/10.1007/BF01980593

Magazzino, C. (2011). Disaggregated public spending, GDP and Money Supply: Evidence for Italy. European Journal of Economics, Finance and Administrative Sciences, 41, 118-131. http://ssrn.com/abstract=2333411.

Magazzino, C. \& Forte, F. (2010). Optimal size of government and economic growth in EU-27. CREI Working paper 04/2010. [http://mpra.ub.uni-muenchen.de/26669

Mann, A. J. (1980). Wagner's law: An econometric test for Mexico. National Tax Journal, 33, 189-201.

Massan, S. S. (2015). Testing Keynesian versus Wagner Hypothesis on the linkage between Government Spending and Economic Growth in Oman. Paper presented at AP15Malaysia Conference, Kuala $\begin{array}{lllll}\text { Lumpur, } & \text { Malaysia, } & \text { 7-9 } & \text { August } & 2015 .\end{array}$ globalbizresearch.org/Malaysia_Conference/pdf/KL553.pdf

Menyah, K. \& Wolde-Rufael, Y. (2012). Wagner's law revisited: A note from South Africa. South African Journal of Economics, 80(2), 200-208. http://www.africabib.org/htp.php?RID=345918576

Mueller, D. C. (2003). Public Choice III. New York: Cambridge University Press.

Musgrave, R. A. (1969). Fiscal systems. New Haven and London: Yale University Press.

Musgrave, R. A. \& Musgrave, B. (1988). Public Finance in Theory and Practice. New York: McGraw-Hill Book Company.

Onder, I. (1974). Turkiye'de kamu Harcamalarinin Syri: 1927-1967. Istanbul: Fakulteler Matbaasi.

Peacock, A. T. \& Wiseman, J. (1961). The growth of public expenditure in the United Kingdom. Princeton, NJ: Princeton University Press.

Perron, P. (1989). The great crash, the oil price shock and the unit root hypothesis. Econometric Research Program, Research Memorandum 338. https://www.jstor.org/stable/1913712

Perron, P. \& Vogelsang, T. J. (1998). Additional tests for a unit root allowing for a break in the trend function at an unknown time. International Economic Review, 39(4), 1073-1100. http://www.jstor.org/stable/2527353

Pesaran, M. H., Shin, Y. \& Smith, R. J. (2001). Bounds testing approaches to the analysis of level relationships. Journal of Applied Econometrics, 16(3), 289-326.

Reimers, E. H. (1992). Comparisons of tests for multivariate cointegration. Statistical papers, 33(1), 335-359. http://link.springer.com/article/10.1007/BF02925336\#Bib1

Rossouw, J., Joubert, F. \& Breytenbach, A. (2014). South Africa's Fiscal Cliff: A Reflection on the Appropriation of Government Resources. Tydskrif vir Geesteswetenskappe, 54(1), 144-162.

National Treasury, South Africa. (2016). Budget Review 2016. http://www.treasury.gov.za/documents/national\%20budget/2016/review/FullReview.pdf

SASSA. (2016). A statistical summary of social grants in South Africa. Retrieved from http://www.sassa.gov.za/index.php/knowledge-centre/statisticalreports?download=518:statistical-report-no-2-of-2016

Sideris, D. (2007). Wagner's Law in 19th Century Greece: A Cointegration and Causality Analysis. Bank of Greece, Working Papers, 64. 
Singh, B. \& Sahni, B. S. (1984). Causality between public expenditure and economic growth in Malaysia. Journal of Economic Development, 23, 71-80.

Ssekuma, R. (2011). A study of cointegration models with applications. Manuscript, University of South Africa.http://uir.unisa.ac.za/bitstream/handle/10500/4821/thesis_ssekuma_r.pdf?sequence=1

Tarschys, D. (1975). The growth of public expenditures - Nine modes of explanation. Scandinavian Political Studies, 10(1), 9-32.

Toda, H. Y. \& Yamamoto, T. (1995). Statistical inference in vector autoregressions with possibly integrated processes. Journal of Econometrics, 66, 225-260.

Wagner, A. (1893). Grundlegung der politischen Ökonomie. 3rd edition, Leipzig: Winter.

Ziramba, E. (2008). Wagner's Law: An Econometric Test for South Africa. South African Journal of Economics, 76 4), 596-606. http://dx.doi.org/10.1111/j.1813-6982.2008.00218.x. 